\title{
Surgical Outcomes of Spinal Tumour: Experiences of 48 Cases at Referral Neurosurgery Hospital in Bangladesh
}

\author{
Shamsuzzaman Mondle ${ }^{*}$, Joynul Islam², Hafizur Rashid², A. T. M. Ashadullah ${ }^{2}$, Fazle Elahi², \\ Bayazidur Rahman ${ }^{2}$, Kazi Hafiz Uddin², Abdullah Yusuf ${ }^{3}$ \\ ${ }^{1}$ Department of Neurosurgery, Shaheed Taj Uddin Ahmed Medical College, Gazipur, Bangladesh \\ ${ }^{2}$ Department of Clinical Neurosurgery, National Institute of Neurosciences \& Hospital, Dhaka, Bangladesh \\ ${ }^{3}$ Department of Microbiology, National Institute of Neurosciences \& Hospital, Dhaka, Bangladesh \\ Email: "szamandr71@gmail.com
}

Received 22 May 2016; accepted 26 July 2016; published 29 July 2016

Copyright (C) 2016 by authors and Scientific Research Publishing Inc.

This work is licensed under the Creative Commons Attribution International License (CC BY).

http://creativecommons.org/licenses/by/4.0/

(c) (i) Open Access

\begin{abstract}
Background: Spinal tumour has a great morbidity. Objective: The purpose of the present study was to see the outcome of the spinal tumour surgery. Methodology: Patients with spinal tumor have undergone surgery in neurospine unit of National Institute of Neurosciences and Hospital, Dhaka, Bangladesh from May 2013 to March 2015 for a period of 23(twenty three) months. Plain X-ray and MRI were done in all cases. All patients have undergone surgery through posterior midline approach. They were evaluated preoperatively and at discharge usually on $10^{\text {th }}$ postoperative day after stitch removal and advised to attend in follow up clinic after 2 months of surgery. Result: 50 59 years age group was observed as most vulnerable for tumor occurrence ( 23 cases, $47.9 \%$ ). The male female ratio was $1: 1.3$. The highest number ( 28 cases, $58.4 \%$ ) of tumor was observed in thoracic region but the highest variety was schwannoma ( 33 cases, $68.7 \%$ ). Initial presentation of patients was pain ( 32 cases, $66.7 \%$ ), motor disturbances ( 9 cases $18.7 \%$ ), sensory disturbances (5 cases $10.4 \%$ ) and sphincter disturbances ( 2 cases $4.2 \%$ ). Symptomatic improvement was in 44 (91.7\%) patients whereas improvement in Frankel Scale was observed in $10(20.8 \%)$ patients during follow up. $4(8.4 \%)$ patients deteriorated and there was no death in this series. Conclusion: In conclusion, majority of the spinal tumour patients are presented with schwannoma with good symptomatic improvement.
\end{abstract}

\section{Keywords}

Spinal Tumour, Schwannoma, Spinal Surgery

\footnotetext{
${ }^{*}$ Corresponding author.
}

How to cite this paper: Mondle, S., Islam, J., Rashid, H., Ashadullah, A.T.M., Elahi, F., Rahman, B., Uddin, K.H. and Yusuf, A. (2016) Surgical Outcomes of Spinal Tumour: Experiences of 48 Cases at Referral Neurosurgery Hospital in Bangladesh. Open Journal of Modern Neurosurgery, 6, 98-104. http://dx.doi.org/10.4236/ojmn.2016.63017 


\section{Introduction}

Spinal tumor is an important inclusion in the complete differential diagnosis for any patient presenting with myelopathy, radiculopathy, neck pain and back pain. Primary tumors that involve the spinal cord or nerve roots are similar to intracranial tumors in cellular type [1].

According to the anatomical location, spinal tumors are conveniently classified as extradural and intradural, though some tumors could be both inside and outside the dura. Intradural tumors could be intramedullary or extramedullary. Benign and malignant neoplasms may arise from intraspinal structures like the meninges, spinal cord, nerve roots, blood vessels and other tissues [2].

Schwannomas and neurofibromas lie either within the spinal canal or "dumbbell” through the intervertebral foramen, on occasions presenting as a mass in the thorax or posterior abdominal wall [3]. Intradural spinal tumors account for only small proportion of CNS tumors with an incidence of 0.3 per 100,000 per year [4]. Twothird of intradural tumors are extramedurllary [5]. Patient with spinal lesions is usually present with any of the three main symptoms: pain both local and radicular, motor disturbances like limb weakness and spasticity and sensory disturbances [6].

Except in the instance of lesions involving conus medullaries or sacral roots of the cauda equina at the junction of lumbar and sacral spine, sphincter disturbance is not an early symptom of spinal cord disease [7]. Plain X-ray and MRI are the usual imaging modalities used to evaluate patients with spinal lesions. The later offers the advantage of being noninvasive and sensitive in detection of the most lesions. One disadvantage of MRI is the fact that some patients are unable to tolerate the close confines of the MR imaging system. Another disadvantage is that even a small amount of patient's motion can significantly degrade images [8]-[14]. Outcome predictors of these tumor's surgery usually include age of the patients, duration of symptoms, pre-operative functional status, size of tumors, severity of cord compression, tumor cord relationship, extent of tumor removal, per operative and also post-operative complocations [9] [13]. The surgery should better carry out by single surgical team employing microsurgical techniques when necessary. Great effort should be made to remove the tumors completely [10]. Therefore, the purpose of the present study was to see the outcome of the spinal tumour surgery.

\section{Methodology}

This study was a case series which was carried out in the National Institute of Neurosciences and Hospital, Dhaka, Bangladesh under the care of Neuro spine unit from May 2013 and March 2015 for a period of 23 (twenty three) months. Patients had surgery for spinal tumors. The patients were evaluated both clinically and radiologically on admission, first POD, at discharge and in follow up clinic as well. All patients have undergone surgery through posterior midline approach. Outcome was measured in Frankel scale.

\section{Results}

A total number of 48 patients were recruited for this study. Total tumor removal was achieved in $75 \%$ cases. Majority of the study population are in the age group of 23 (47.9\%) cases followed by 13 (27.1\%) cases (Table 1).

In this study, female was predominant than male which was 27 and 21 cases respectively. Among female maximum were in the thoracic region tumour which was 18 cases followed by 4 cases in cervical region. Among male patients, majority tumour found in thoracic region which was 10 cases followed by 5 cases in cervical region (Table 2).

Pain was the main complaints of the patients which was 32 (66.7\%) cases followed by 9 (18.7\%) cases of motor disturbances (Table 3).

Spasticity was the most common clinical sign which was 35 (72.9\%) cases followed by muscular weakness which was 15 (31.2\%) cases (Table 4).

Majority of the tumour were in the lateral side of the spinal cord which was 32 (66.7\%) cases followed by posterior which was $13(27.1 \%)$ cases (Table 5).

Majority were reported 12 to 15 months duration of symptoms which was 15 (31.2\%) cases followed by 9 to 12 months and 15 to 18 months which were 8 (16.6\%) cases in each group (Table 6).

Total extent of removal of tumour was performed in 36 (75.0\%) cases; however, gross total removal was performed in 7 (14.5\%) cases (Table 7$)$.

Schwannoma was the most common tumour which was 33 (68.7\%) cases followed by neurofibroma and meningioma which were 7 (14.5\%) cases and 3 (6.2\%) cases respectively (Table 8 ). 
Table 1. Age distribution of the patients.

\begin{tabular}{ccc}
\hline Age Group & Frequency & Percentage \\
\hline$<20$ & 3 & 6.2 \\
$20-30$ & 1 & 2.1 \\
$30-40$ & 3 & 6.2 \\
$40-50$ & 13 & 27.1 \\
$50-60$ & 23 & 47.9 \\
$60-70$ & 5 & 10.4 \\
$>70$ & 0 & 0 \\
Total & $\mathbf{4 8}$ & $\mathbf{1 0 0}$ \\
\hline
\end{tabular}

${ }^{*}$ Figures in the parentheses denote corresponding percentage; Range: 14 - 68 years; Mean \pm SD: 51.3 years.

Table 2. Location of tumors in relation with gender.

\begin{tabular}{cccc}
\hline Region & Male & Female & Total \\
\hline Cervical & 5 & 4 & $9(18.7 \%)$ \\
Thoracic & 10 & 18 & $28(54.8 \%)$ \\
Lumbar & 3 & 2 & $5(10.4 \%)$ \\
Cervicothoracic & 2 & 1 & $3(6.2 \%)$ \\
Thoracolumbar & 0 & 1 & $1(2.1 \%)$ \\
Lumbosacral & 1 & 1 & $2(4.2 \%)$ \\
Total & $\mathbf{2 1}$ & $\mathbf{2 7}$ & $\mathbf{4 8}(\mathbf{1 0 0 . 0} \%)$ \\
\hline
\end{tabular}

${ }^{*}$ Figure in the parenthesis denotes corresponding percentage.

Table 3. Initial symptoms of the patients.

\begin{tabular}{ccc}
\hline Symptoms & Frequency & Percentage \\
\hline Pain & 32 & 66.7 \\
Motor disturbances & 9 & 18.7 \\
Sensory disturbances & 5 & 10.4 \\
Sphincter disturbances & 2 & 4.2 \\
Total & $\mathbf{4 8}$ & $\mathbf{1 0 0}$ \\
\hline
\end{tabular}

Table 4. Clinical signs of the patients.

\begin{tabular}{ccc}
\hline Clinical signs* & Frequency & Percentage \\
\hline Muscular weakness & 15 & 31.2 \\
Spasticity & 35 & 72.9 \\
Sensory level & 10 & 20.8 \\
Impaired joint position and vibration senses & 10 & 20.8 \\
Impaired two points discriminations & 8 & 16.6 \\
\hline
\end{tabular}

${ }^{*}$ Multiple occurrences of signs.

Table 5. Relation of tumors with cord in finding of MRI.

\begin{tabular}{ccc}
\hline Location of tumors & Frequency & Percentage \\
\hline Anterior & 3 & 6.2 \\
Posterior & 13 & 27.1 \\
Lateral & 32 & 66.7 \\
Total & 48 & 100 \\
\hline
\end{tabular}


Table 6. Distribution of study population according to duration of symptoms.

\begin{tabular}{ccc}
\hline Duration (months) & Frequency & Percentage \\
\hline$<3$ & 2 & 4.2 \\
$3-6$ & 4 & 8.4 \\
$6-9$ & 5 & 10.4 \\
$9-12$ & 8 & 16.6 \\
$12-15$ & 15 & 31.2 \\
$15-18$ & 8 & 16.6 \\
$18-24$ & 4 & 8.4 \\
$>24$ & 2 & 4.2 \\
Total & $\mathbf{4 8}$ & $\mathbf{1 0 0}$ \\
\hline
\end{tabular}

Range: 2 - 25 months; Mean: 12.8 months.

Table 7. Extent of tumor removal among the study population.

\begin{tabular}{ccccc}
\hline $\begin{array}{c}\text { Extent of } \\
\text { removal }\end{array}$ & Extradural & $\begin{array}{c}\text { Intradural } \\
\text { extramedullary }\end{array}$ & $\begin{array}{c}\text { Intradural } \\
\text { intramedullary }\end{array}$ & Total \\
\hline Total & 4 & 32 & 0 & $36(75.0 \%)$ \\
Gross total & 2 & 5 & 0 & $7(14.5 \%)$ \\
Near total & 0 & 0 & 3 & $3(6.2 \%)$ \\
De-bulking & 0 & 0 & 2 & $2(4.2 \%)$ \\
Grand total & 6 & 37 & 5 & $48(100.0 \%)$ \\
\hline
\end{tabular}

Table 8. Histopathology findings of the spinal tumour.

\begin{tabular}{ccccc}
\hline Type & Cervical & Thoracic & Lumbar & Total \\
\hline Schwannoma & 9 & 22 & 2 & $33(68.7 \%)$ \\
Neurofibroma & 2 & 4 & 1 & $7(14.5 \%)$ \\
Meningioma & 1 & 2 & 0 & $3(6.2 \%)$ \\
Lipoma & 1 & 0 & 1 & $2(4.2 \%)$ \\
Ependymoma & 0 & 1 & 1 & $2(4.2 \%)$ \\
Astrocytoma & 1 & 0 & 0 & $1(2.1 \%)$ \\
Total & $\mathbf{1 4}$ & $\mathbf{2 9}$ & $\mathbf{5}$ & $\mathbf{4 8 ~ ( 1 0 0 . 0 \% )}$ \\
\hline
\end{tabular}

One of the notable complications was post-operative CSF leakage in 3 cases which was treated conservatively. Our follow up scenario was miserable. All patients were evaluated only at discharge. Only 1 (2.1\%) patient attended at follow up clinic at the end of $4^{\text {th }}$ month of surgery (Table 9 ).

Only 4 (8.4\%) patients were deteriorated and 14 (29.2\%) cases were improved during early post-operative period attended at follow up clinic after discharge. During subsequent follow up the change was towards improvement. One of the notable complications was post-operative CSF leakage (6.3\%) which was managed conservatively (Table 10 ).

It was mentioned earlier that post-operative outcome was measured in Frankel scale. There was no patient in grade A both pre and post operatively. In grade B there was 2 patients both pre and post operatively. In C, D and E grade pre-operatively there was 5, 8 and 33 patients and post-operatively 2, 4, 40 patients respectively. Bolded figures indicate the situations where pre and early post-operative grading was unchanged. Figures right to the bolded figures indicate early post-operative improvement. Figures left to the bolded figures indicate early post-operative deterioration (Table 11).

\section{Discussion}

Intradural extramedullary spinal tumors are the commonest of all intraspinal tumors. The predilection of menin- 
Table 9. Follow up scenario.

\begin{tabular}{ccc}
\hline Time of follow up & Frequency & Percentage \\
\hline Early post-operative & 48 & 100 \\
Within 1 month & 14 & 29.2 \\
Within 2 months & 4 & 8.4 \\
Within 4 months & 1 & 2.1 \\
Within 6 months & 0 & 0 \\
After 6 months & 0 & 0 \\
\hline
\end{tabular}

Table 10. Early relief of symptoms.

\begin{tabular}{ccccc}
\hline $\begin{array}{c}\text { Symptomatic } \\
\text { change }\end{array}$ & ED tumors & IDEM tumors & IDIM tumors & Total \\
\hline Improved & 4 & 6 & 0 & $10(20.8 \%)$ \\
Improving & 2 & 31 & 1 & $34(70.8 \%)$ \\
No change & 0 & 0 & 0 & $0(0.0 \%)$ \\
Deterioration & 0 & 0 & 4 & $4(8.4 \%)$ \\
Total & 6 & 37 & 5 & $48(100.0 \%)$ \\
\hline
\end{tabular}

Table 11. Early post-operative outcome in Frankel scale.

\begin{tabular}{cccccc}
\hline \multirow{2}{*}{ Preoperative Frankel grade } & \multicolumn{5}{c}{ Early post-operative Frankel grade } \\
\cline { 2 - 6 } & A & B & C & D & E \\
A & & & & & \\
B & & $\mathbf{1}$ & 1 & & \\
C & 1 & 1 & $\mathbf{1}$ & 2 \\
D & & & 1 & 7 \\
E & & & 2 & $\mathbf{3 1}$ \\
\hline
\end{tabular}

gioma for thoracic spine in women in $5^{\text {th }}$ decades or beyond is well documented. The rarity of their presence in lumbar spine is similarly well documented [6]. But in this series, meningioma was only $6.2 \%$ and there was no meningioma in lumbar region. Schwannoma is evenly distributed throughout the spinal axis [5]. But distribution of neurofibroma throughout the spinal canal is proportional to the length of each. Both of these nerve sheath tumors are common in $3^{\text {rd }}$ to $5^{\text {th }}$ decade of life and have slight male preponderance [8].

In this series there was 27.3\% (09 cases), 66.7\% (22 cases) and 6\% (02 cases) cervical, thoracic and lumbar schwannoma and neurofibroma was $28.6 \%$ (02 cases), $57.1 \%$ (04 cases) and $14.2 \%$ (01 cases) respectively. Intramedullary spinal cord tumors are rare lesions and constitute only $4 \%-10 \%$ of all primary central nervous system tumors. These are less common in adults than in children and constitute $20 \%$ and $35 \%$ respectively of all intraspinal tumors [12]. In this series intramedullary spinal tumor is $10.5 \%$ with lipoma $4.2 \%$ (02 cases), ependymoma 4.2\% (02 cases) and astrocytoma 2.1\% (01 cases) respectively.

Pain (32 cases 66.7\%) was the commonest initial symptom in all spinal levels. Next to pain, $18.7 \%$ (09 cases) $10.4 \%$ (05 cases) and $4.2 \%$ (02 cases) patients presented with motor disturbances, sensory disturbances and sphincter disturbances respectively as initial symptom. This report can be compared to the report of other series [10] where pain, motor and sensory disturbances were present as initial symptom in $60 \%, 24.2 \%$ and $15.8 \%$ cases respectively.

Both impaired joint position and vibration sense was found in 10 cases (20.8\%). A sensory level was present in 10 cases (20.8\%) and both spastic gait and reflex abnormality were in 35 cases (72.9\%) before surgery. All patients were investigated with plain X-ray and MRI. Plain X-rays were apparently normal other than scoliosis only in 2 of the thoracic cases. MRI confirmed the location, stated tumor cord relationship and also provided clues to histopathological diagnosis.

The goal of the treatment for spinal cord and cauda equina tumors is to resect the lesion totally without injur- 
ing the spinal cord, cauda equina, or spinal nerve roots, or exacerbating the patient's neurologic deficit [11]. The operative objective in all cases was to attempt complete excision through posterior midline approach but this was not achievable in 12 cases (25\%). Out of these, 5 cases were IDEM, 2 cases were anteriorly placed schwannoma in the cervical spine and it was thought that neuroaxix might be compromised by extensive resection. The remaining 3 cases were neurofibroma whose outline could not be cleared due to firm adhesion with surrounding structures. This result is comparable to other series [4] where complete excision was not possible in 15.8\% cases. In Albanese and platania's (2002) series complete excision was not possible in 6\% of schwannomas. In other 7 cases (02 ED and 05 IDIM) outline was not demarcated clearly.

In terms of complications, CSF leakage was the notable problem. In this series, there were $6.3 \%$ (03 patients) cases of CSF leakage. These were in Meningioma group and in 2 cases duroplasty was done during surgery. Both patients were treated conservatively by maintaining prone position. No patient developed meningitis and there was no postoperative death in this series. CSF leakage and subsequent meningitis was the greatest problem in the series of both Mahdy et al. (1999) and Jenkinson et al (2006). There was also 2.6\% post-operative death in the series of Jenkinson et al. (2006). In two cases of this series one schwannoma and another Neurofibroma, nerve roots were sacrificed as an attempt of complete surgical excision. However, these cases shown no early post-operative neurological deficit. This was possibly due to the reason that the nerve roots giving rise to extramedullary spinal tumors were nonfunctional at the time of surgery [4].

In terms of symptomatic relief, complete early postoperative at $10^{\text {th }}$ post-operative day relief was observed in 10 cases (20.8\%). There was neither complete recovery of motor function nor complete improvement of sensory disturbance during this period. Partial improvement of pain, motor and sensory disturbance was noticed in 34 cases $(70.8 \%)$. Only one patient with preoperative sphincter disturbance noticed little improvement at discharge. There was $8.4 \%$ symptomatic deterioration in this series.

In terms of functional outcome, it was considered that the Frankel grading system has provided much more useful way to display the individual and collective changes following surgery which do not unexpectedly depend on the deficit at time of presentation as well as effects of surgery [10].

Many factors have influenced the outcome of surgical treatment. The most important are pre-operative functional status of the patients, histological characteristics of tumors, spinal segment affected, extent of cord compression and degree of decompression as well. The most difficulty encountered during surgery was complete tumor removal in some cases especially intramedullary lesions. Out of 48 patients in this series, 33 patients were in grade "E", i.e. in the last grade where there was no question of changing functional grade. So that functional grades were changeable in remaining 15 patients. According to the Frankel grading score 6.3\% (03 patients) cases of this series were improved in different grades at discharge. There were 8 cases $(16.8 \%)$ where early postoperative grades remained unchanged. There were 4 patients who developed early postoperative functional deficit in this series. These deficits are probably due to injury to the cord during surgery. In the series of Jenkinson et al. (2006), early postoperative improvement was 32\% and in 3.9\% cases there developed deficit during this period. This discrepancy may be due to longer duration of study and large sample size of the latter series.

\section{Conclusion}

In conclusion, it has been found that older age group is the most vulnerable for spinal tumor occurrence with predominance of female. The highest number of tumor has been observed in thoracic region with schwannoma. Symptomatic improvement has been observed in majority patients. Detailed clinical and imaging evaluation can be used to provide optimal surgical approach and tumor removal as well for individual patients.

\section{Funding Agency}

None.

\section{Conflict of Interest}

There is no conflict of interest to any of the authors.

\section{Contribution to Authors}

MSM has involved from protocol preparation, data collection up to manuscript writing. MSM, MJI, MMHR, 
ATMA, MFE have contributed in the surgical procedure. MBR \& KHU have involved in the assistance of the operation. MAY has revised the manuscript.

\section{References}

[1] Parsa, A.T., Lee, J., Parney, I.F., Weinstein, P., McCormick, P.C. and Ames, C. (2004) Spinal Cord and Intradural Extraparenchymal Spinal Tumours: Current Best Care Practices \& Strategies. Journal of Neuro-Oncology, 69, 291-318. http://dx.doi.org/10.1023/B:NEON.0000041889.71136.62

[2] Ramamurthi, B. and Rao, S.B. (1996) Tumours of the Spinal Cord and Cauda Equina. In: Ramamurthi, B. and Tandon, P.N., Eds., Text Book of Neurosurgery, 2nd Edition, Vol-2, B.I Churchill Livingstone Pvt. Ltd., New Delhi, 707-742.

[3] Lindsay, K.W. and Bone, L. (2004) Spinal Cord and Root Compression. In: Neurology and Neurosurgery Illustrated, 4th Edition, Churchill Livingstone, Philadelphia, 393-401.

[4] Jenkinson, M.D., Simpson, C., Nicholas, R.S., Miles, J., Findlay, G.F.G. and Pigott, T.J.D. (2006) Outcome Predictors and Complications in the Management of Intradural Spinal Tumours. European Spine Journal, 15, 203-210. http://dx.doi.org/10.1007/s00586-005-0902-x

[5] McCormick, P.C., Post, K.D. and Stein, B.M. (1990) Intradural Extramedullary Tumours in Adults. Neurosurgery Clinics of North America, 1, 591-608.

[6] King, A.T., Sharr, M.M., Gullarq, R.W. and Bartlett, J.R. (1998) Spinal Meningiomas: A 20-Year Review. British Journal of Neurosurgery, 12, 521-526.

[7] Woolsey, R.M. and Young, R.R. (1995) The Clinical Diagnosis of Disorders of the Spinal Cord. In: Young, R.R. and Woolsey, R.M., Eds., Diagnosis and Management of Disorders of the Spinal Cord, W.B. Saunders Company, Philadelphia, 135-152.

[8] Provenzale, J.M. and Taveras, J.M. (1994) Clinical Cases in Neuroradiology. Lea \& Febiger, Pennsylvania, 169-174, 222-227.

[9] Albanese, V. and Platania, N. (2002) Spinal Intradural Extramedullary Tumours. Personal Experience. Journal of Neurosurgical Sciences, 46, 18-24

[10] Mahdy, W.E., Kane, P.J., Powell, M.P. and Crockard, H.A. (1999) Spinal in Tradural Tumours: Part-I-Extramedullary. British Journal of Neurosurgery, 13, 550-557.

[11] Asazuma, T., Toyam, Y., Watanabe, M., Suzuki, N., Fujimurq, Y. and Hirabayashi, K. (2003) Clinical Features Associated with Recurrence of Tumours of the Spinal Cord and Cauda Equin. Spinal Cord, 41, 85-89. http://dx.doi.org/10.1038/sj.sc.3101394

[12] Bostrom, A., Kanther, N.C., Grote, A. and Bostrom, J. (2014) Management and Outcome in Adult Intramedullary Spinal Cord Tumors: A 20-Year Single Institution Experience. BMC Research Notes, 7, 908. http://dx.doi.org/10.1186/1756-0500-7-908

[13] Nambiar, M. and Kavar, B. (2012) Clinical Presentation and Outcome of Patients with Intradural Spinal Cord Tumors. Journal of Clinical Neuroscience, 14, 262-266. http://dx.doi.org/10.1016/j.jocn.2011.05.021

[14] Rcith, W. and Yilamz, U. (2011) Extradural Tumors. Der Radiologe, 51, 1018-1024. http://dx.doi.org/10.1007/s00117-011-2152-8 


\section{Submit or recommend next manuscript to SCIRP and we will provide best service for you:}

Accepting pre-submission inquiries through Email, Facebook, LinkedIn, Twitter, etc.

A wide selection of journals (inclusive of 9 subjects, more than 200 journals)

Providing 24-hour high-quality service

User-friendly online submission system

Fair and swift peer-review system

Efficient typesetting and proofreading procedure

Display of the result of downloads and visits, as well as the number of cited articles

Maximum dissemination of your research work

Submit your manuscript at: http://papersubmission.scirp.org/ 